\title{
Moderating effects of salivary testosterone levels on associations between job demand and psychological stress response in Japanese medical workers
}

\author{
Kumi HIROKAWA ${ }^{1,2 *}$, Machiko MIWA ${ }^{2}$, Toshiyo TANIGUCHI ${ }^{3}$, \\ Masao TSUCHIYA ${ }^{4}$ and Norito KAWAKAMI ${ }^{5}$
}

\author{
${ }^{1}$ Okayama University Graduate School of Medicine, Dentistry, and Pharmaceutical Sciences, Hygiene and \\ Preventive Medicine, Japan \\ ${ }^{2}$ Department of Nursing, Baika Women's University, Japan \\ ${ }^{3}$ Department of Welfare System and Health Science, Okayama Prefectural University, Japan \\ ${ }^{4}$ National Institute of Occupational Safety and Health, Japan \\ ${ }^{5}$ Department of Mental Health and Department of Psychiatric Nursing, The University of Tokyo, Japan
}

Received June 19, 2015 and accepted November 4, 2015

Published online in J-STAGE December 1, 2015

\begin{abstract}
Levels of job stress have been shown to be inversely associated with testosterone levels, but some inconsistent results have been documented. We investigated the moderating effects of testosterone levels on associations between job stress-factors and psychological stress responses in Japanese medical workers. The participants were 63 medical staff $(20$ males and 43 women; mean age: 30.6 years; $\mathrm{SD}=7.3$ ) in Okayama, Japan. Their job-stress levels and psychological stress responses were evaluated using self-administered questionnaires, and their salivary testosterone collected. Multiple regression analyses showed that job demand was positively associated with stress responses in men and women. An interaction between testosterone and support from colleagues had a significant effect on depression and anxiety for women. In women with lower testosterone levels, a reducing effect of support from colleagues on depression and anxiety was intensified. In women with higher testosterone levels, depression and anxiety levels were identical regardless of support from colleagues. Testosterone may function as a moderator between perceived work environment and psychological stress responses for female medical workers.
\end{abstract}

Key words: Salivary testosterone, Job demand, Job control, Psychological stress response, Moderator

\section{Introduction}

Medical workers often encounter challenges at work, such as physical demands, occupational demands on precision, role conflicts, ergonomic shortcomings, and relationships with patients ${ }^{1}$, that can result in high psychological stress levels. In the demand-control model of job strain,

*To whom correspondence should be addressed.

E-mail: k-umi@umin.ac.jp

(C)2016 National Institute of Occupational Safety and Health workers who have high psychological demands but low job control are considered to have a "high job strain"2,3). This model of job strain has been investigated as being predictive of negative health and psychological outcomes. Johnson and $\mathrm{Hall}^{4)}$ focused on the moderating effect of social support; they expanded the demand-control model of job strain ${ }^{2)}$ to include a social-support dimension called the "demand-control-support model". According to one study investigating the associations between job demand, job control, social support, and depressive symptoms in Japanese nurses, high job strain, low job control, low sup- 
port from supervisors, and long working hours were associated with depressive symptoms ${ }^{5}$.

Recent studies have focused attention on an association between job stress and testosterone levels ${ }^{6-8)}$. Testosterone is thought to be an intermediary stress-sensitive hormone. Chronic stress decreases blood levels of testosterone ${ }^{9-11)}$ and suppresses steroidogenesis in the testicles ${ }^{9}$. Reduced synthesis of testicular androgens may be caused by glucocorticoids and adrenocorticotropic hormones ${ }^{12)}$. Glucocorticoids enhance apoptosis of Leydig cells ${ }^{13,14)}$, and increased apoptosis in the gonads is associated with decreases in testosterone levels in blood ${ }^{15)}$. Levels of job stress have been shown to be inversely associated with testosterone levels. For example, total plasma testosterone levels increase when job strain diminishes in working men $^{6}$. Salivary levels of testosterone have been positively associated with higher job control in female teachers ${ }^{16}$. In a study on male shift workers ${ }^{17}$, dissatisfaction with the shift system was related to lower testosterone levels in serum. In males working for long hours (84-h per week), testosterone levels showed a significant decrease between workday-5 and workday- $7^{18)}$. In one review ${ }^{10)}$, an adverse psychosocial working environment was found to be robustly associated with reduced serum levels of testosterone.

However, inconsistent results have been documented. In a longitudinal study, testosterone levels increase with negative psychosocial work conditions are lacking ${ }^{7}$. For workers in human-service organizations such as providing care or education, an association between job strain and testosterone levels has not been observed ${ }^{19)}$. Reorganization of work sites (which cause worries about unemployment) has been shown to increase testosterone levels at three-year follow-up ${ }^{20)}$. Possible reasons for inconsistent results among studies on job stress and testosterone levels may be due to differences in study design (e.g., cross-sectional, longitudinal). Differences in the characteristics of study participants, such as age, occupation (office workers or manual workers), and health status could affect results. Among those studies, an investigation of sex differences is not available.

Alternatively, testosterone levels may not be directly associated with job stress but instead may function as a "moderator" between psychological stress levels and job performance. For example, a study on testosterone levels in firefighters showed that testosterone appeared to be a moderator between psychological personality traits and job performance, which included firefighting and providing medical services ${ }^{21)}$. Specifically, firefighters with high testosterone levels were facilitated to maintain their performance more than those with low testosterone levels ${ }^{21)}$. In Hockey's ${ }^{22)}$ compensatory regulatory-control model, when job demand increases, extra compensatory effort is required to maintain performance. This extra compensatory effort is associated with physiological and psychological costs such as increased sympathetic activity, fatigue, and irritability ${ }^{22}$. When exposed to high job stress, persons with higher testosterone levels (high reserves of energy) may have lower psychological costs (psychological stress responses) than those with lower testosterone levels. However, there is little evidence on the moderating effects of testosterone on associations between job stress and psychological stress responses.

Lower testosterone levels in the sera of male medical residents compared with other hospital personnel (including a pathology resident and non-physicians) have been noted $^{23)}$. The higher job stress of junior doctors compared with other hospital personnel has been postulated to explain this difference ${ }^{23)}$. Serum testosterone levels in surgeons have been shown to increase during cancer surgery ${ }^{24)}$. Specific medical conditions related to job stress and aggression in surgeons was discussed in that study. A study on the association between job stress and testosterone levels in other medical workers (e.g., nurses, physiotherapists, care staff) has not been carried out.

The first aim of the present study was to investigate associations between job-stress factors and testosterone levels in Japanese medical workers. We hypothesized that high levels of job-stress were associated with low levels of testosterone. The second aim was to discover if there was an interaction effect of job-stress levels and testosterone levels on psychological stress responses. Specifically, if job-stress factor levels were high, medical workers with low testosterone levels may have higher psychological stress responses. Considering the sex differences in testosterone and psychological stress levels, we analyzed men and women separately.

\section{Participants and Methods}

\section{Participants}

Individuals were recruited (through the administrators of two hospitals in a local area) to be volunteers in a study focusing on mental-health education in Okayama, Japan. One week before starting health education, a baseline survey was conducted. Of all hospital staff (except physicians) asked to complete questionnaires, 102 staff ( 27 men and 75 women) did so. Saliva data from 71 medical staff ( 22 men 
Table 1. Participants' characteristics and means (SDs) of variables

\begin{tabular}{|c|c|c|c|c|}
\hline & Men & Women & $\chi^{2}$ & $p$ \\
\hline Number & 20 & 43 & & \\
\hline Education & & & 6.22 & 0.10 \\
\hline High school (\%) & 5.0 & 9.3 & & \\
\hline Vocational college $(\%)$ & 25.0 & 44.2 & & \\
\hline $\begin{array}{l}\text { Junior college or national vocational } \\
\text { college }(\%)\end{array}$ & 15.0 & 23.3 & & \\
\hline University $(\%)$ & 55.0 & 23.3 & & \\
\hline Occupation & & & 12.38 & 0.030 \\
\hline Nurses $(\%)$ & 5.0 & 31.9 & & \\
\hline Care staff $(\%)$ & 0.0 & 7.0 & & \\
\hline Physical therapist (\%) & 35.0 & 14.0 & & \\
\hline Laboratory technician (\%) & 15.0 & 9.3 & & \\
\hline Medical processor $(\%)$ & 25.0 & 18.6 & & \\
\hline Other $(\%)$ & 20.0 & 9.3 & & \\
\hline Magagement position (\%) & 0.0 & 0.0 & & \\
\hline Married (\%) & 45.0 & 48.8 & 0.08 & 0.78 \\
\hline Never smoked $(\%)$ & 60.0 & 76.7 & 1.88 & 0.17 \\
\hline Alcohol use ( $>=$ once a week) $(\%)$ & 60.0 & 25.6 & 6.98 & 0.008 \\
\hline Physical active ( $>=$ once a week) (\%) & 70.0 & 18.6 & 15.87 & $<0.001$ \\
\hline \multirow[t]{2}{*}{ Medial history (\%) } & 5.0 & 9.3 & 0.35 & 0.56 \\
\hline & \multicolumn{2}{|c|}{ Mean (SD) } & t value & $p$ \\
\hline Testosterone (ng/mL) & $0.27(1.58)$ & $0.21(1.46)$ & 2.55 & 0.013 \\
\hline Age & $29.0(5.9)$ & $31.5(8.0)$ & 1.26 & 0.21 \\
\hline Period of service (years) & $4.07(3.64)$ & $6.67(5.55)$ & 4.26 & 0.030 \\
\hline Job demands & $34.9(3.4)$ & $35.9(5.2)$ & 0.90 & 0.37 \\
\hline Job control & $69.8(9.5)$ & $69.0(8.5)$ & 0.33 & 0.75 \\
\hline Support from supervisors & $11.8(2.1)$ & $12.5(2.5)$ & 0.70 & 0.49 \\
\hline Support from colleagues & $12.5(1.6)$ & $12.3(2.3)$ & 0.30 & 0.76 \\
\hline Stress responses (total) & $36.6(12.4)$ & $33.9(11.8)$ & 0.80 & 0.42 \\
\hline Depression and anxiety & $12.5(4.5)$ & $11.4(4.6)$ & 0.87 & 0.39 \\
\hline Bad-tempered and angered & $12.0(4.5)$ & $11.3(4.6)$ & 0.50 & 0.62 \\
\hline Apathetic & $12.2(4.4)$ & $11.2(4.1)$ & 0.81 & 0.42 \\
\hline
\end{tabular}

and 49 women) were collected. None of the participants had a history of diseases of the thyroid, parathyroid, or adrenal glands. Because two women were menopausal, they were excluded from the analyses. Finally, 63 medical staff ( 20 men and 43 women) was analyzed by excluding missing data.

Table 1 shows participant characteristics and mean scores (SDs) of testosterone levels, age, job demand, job control, and support at work according to sex. The most prevalent occupation for men was physiotherapist, and that for women was nurse. Low proportions of participants graduated from high school, whereas some participants had graduated from vocational college to obtain occupational qualifications. None of the participants were managers. More than $40 \%$ of men and women were married. Significant differences in sex were found with respect to occupation $\left(\chi^{2}(5)=12.38, p=0.030\right)$, alcohol use $\left(\chi^{2}(1)=6.98\right.$, $p=0.008)$, physical activity $\left(\chi^{2}(1)=15.87, p<0.001\right)$, testosterone levels ( $\mathrm{t}(61)=2.55, p=0.013)$, and period of service $(\mathrm{t}(53.85)=4.26, p=0.030)$. In terms of occupation, the proportion of nurses was higher and the period of service was longer for women than for men. Proportions of physically active participants and alcohol users were higher, and testosterone levels were higher, for men than for women.

This study was conducted after obtaining approval from the Ethics Committee of Okayama University Graduate School of Medicine, Dentistry, and Pharmaceutical Sciences and from the ethics committees of the participants' hospitals. The instructor explained the outline of the study to participants. All participants signed informed consent forms before enrolment into the study.

\section{Questionnaire}

Job content. A Japanese version of the Job Content Ques- 
tionnaire (JCQ) was used to measure the characteristics of work environments. The Japanese version of the JCQ has been validated and tested for reliability ${ }^{25)}$. The questionnaire consists of scales related to job control (nine items), job demand (five items), supervisory support (four items), and co-worker support (four items). Response options using the Likert scale from 1 (completely disagree) to 4 (completely agree) were used. Each scale score was calculated by summing the scores according to JCQ guidelines $^{26)}$. Cronbach's alpha coefficients among study participants were 0.65 for job control, 0.61 for job demand, 0.92 for supervisor support, and 0.82 for co-worker support.

Stress responses. Stress response scale-1 $18^{27)}$ was used to evaluate stress-response levels; this scale has 18 items. We asked whether the participants felt those stress responses for the previous 2 days, choosing from 0 ("not at all") to 3 ("strongly"). Sample items were "I feel sadness", "I feel anxious", and "I feel anger". Subscales were "Depression and anxiety", "Aggressive response", and "Apathetic response". Cronbach's alpha coefficients were 0.94 for total score, 0.86 for "Depression and anxiety", 0.88 for "Aggressive response", and 0.85 for "Apathetic response".

Salivary testosterone. Saliva samples were collected using saliva collection test tubes (Sceti. Co., Ltd, Tokyo, Japan) at 10 am on the day of the health-education session. Participants were instructed to place a piece of cotton on their tongue to collect saliva. They were asked to hold the cotton as still as possible for $2 \mathrm{~min}$ and were timed precisely by a lecturer using a watch. After $2 \mathrm{~min}$, participants removed the cotton, returning it to the tubes. After saliva samples were collected, they were spun in an ultracentrifuge and frozen immediately. All samples were assayed using an electrochemical-luminescence-immunoassay test (Medical \& Biological Laboratories Co., Ltd, Nagoya, Japan) following manufacturer instructions. The lower limit of detection of the assay was $0.05 \mathrm{ng} / \mathrm{mL}$.

To confirm the reliability of testosterone measurements, second saliva samples were collected from 19 participants ( 2 men and 17 women) out of the original 71 participants after $15 \mathrm{~min}$. No significant change was observed when a $t$-test was conducted. Given the distribution of the rate of s-testosterone secretion in samples, natural log transformation was applied before statistical analyses.

\section{Statistical analyses}

Testosterone was examined using a natural log transformation; geometric means are presented. To compare between men and women, a Student's $t$-test was conducted for continuous variables and a chi-square test for categori- cal variables. Pearson's correlation coefficients were computed for continuous variables by sex. Multiple regression analyses were undertaken to examine associations between testosterone levels and lifestyle variables and job-stress factors. Multiple regression analyses were carried out to examine associations between stress responses, job-stress factors, and testosterone levels with adjustment for potential confounding factors. Multiplicative variables of testosterone and job-stress factors (i.e., job demand, job control, support from supervisor, support from colleagues) were calculated. Each multiplicative variable was taken into the model to examine an interaction effect. Continuous variables were mean-centered ${ }^{28)}$ and graphic displays of the regression models were created to further examine the interaction effects ${ }^{29}$. Regression lines and predicted values illustrating the significant interactions were constructed from the intercepts, unstandardized regression coefficients, mean values, and standard deviations (SDs) ${ }^{30}$. Scores (to six significant figures for accuracy) were plotted at low (1 $\mathrm{SD}$ below the mean) and high values (1 SD above the mean $)^{30)}$. All tests were two-tailed and $p<0.05$ was considered significant. Statistical analyses were undertaken using SPSS v22.0 (IBM, Armonk, NY, USA).

\section{Results}

Pearson's correlation coefficients are shown in Table 2. In men, testosterone was positively correlated with apathetic response. Job demand was positively correlated with the total score of stress responses, depression and anxiety, aggressive response, and apathetic response, whereas support from supervisor was negatively correlated with those stress responses. Period of service was positively correlated with age, job demand, the total score of stress responses, and aggressive responses. The period of service was negatively correlated with support from supervisors. In women, testosterone was negatively correlated with age. Age was negatively correlated with job control, and support from colleagues. Job demand was positively correlated with the total score of stress responses and aggressive response. Support from supervisor and support from colleagues were negatively correlated with the total score of stress responses, depression and anxiety, and aggressive response. Period of service was positively correlated with age, whereas it was negatively correlated with support from colleagues.

\section{Associations between job-stress factors and testosterone levels}

Table 3 shows the results of multiple regression analyses 
Table 2. Pearson's correlation coefficients between testosterone, age, job demand, job control, support from supervisor, and support from colleagues

\begin{tabular}{lcccccccccccc}
\hline & $(1)$ & $(2)$ & $(3)$ & $(4)$ & $(5)$ & $(6)$ & $(7)$ & (8) & (9) & (10) & (11) \\
\hline (1) Testosterone & & 0.21 & 0.10 & -0.08 & -0.16 & -0.22 & 0.00 & 0.40 & 0.36 & 0.26 & $0.50^{*}$ \\
(2) Age & $-0.35^{*}$ & & $0.52^{*}$ & 0.04 & 0.09 & -0.28 & -0.07 & 0.16 & 0.07 & 0.24 & 0.14 \\
(3) Periods of service & -0.13 & $0.67^{* *}$ & & $0.59^{* *}$ & -0.34 & $-0.61^{* *}$ & -0.42 & $0.47^{*}$ & 0.42 & $0.50^{*}$ & 0.38 \\
(4) Job demand & 0.04 & 0.06 & 0.12 & & -0.04 & -0.29 & -0.14 & $0.57^{* *}$ & $0.56^{*}$ & $0.50^{*}$ & $0.52^{*}$ \\
(5) Job control & 0.20 & $-0.33^{*}$ & 0.02 & 0.07 & & $0.61^{* *}$ & 0.35 & -0.30 & -0.19 & -0.36 & -0.29 \\
(6) Support from supervisor & 0.19 & -0.29 & -0.10 & -0.12 & $0.41^{* *}$ & & 0.36 & $-0.55^{*}$ & $-0.53^{*}$ & $-0.54^{*}$ & $-0.46^{*}$ \\
(7) Support from colleagues & -0.04 & $-0.37^{*}$ & $-0.32^{*}$ & -0.21 & 0.12 & $0.62^{* *}$ & & -0.10 & -0.02 & -0.20 & -0.06 \\
(8) Stress responses (total) & -0.13 & 0.08 & 0.07 & $0.38^{*}$ & -0.22 & $-0.35^{*}$ & $-0.39^{*}$ & & $0.92^{* *}$ & $0.89^{* *}$ & $0.97^{* *}$ \\
(9) Depression and anxiety & -0.05 & 0.15 & 0.08 & 0.28 & -0.29 & $-0.33^{*}$ & $-0.40^{* *}$ & $0.93^{* *}$ & & $0.67^{* *}$ & $0.89^{* *}$ \\
(10) Aggressive & -0.19 & 0.04 & 0.12 & $0.47^{* *}$ & -0.12 & $-0.44^{*}$ & $-0.47^{* *}$ & $0.86^{* *}$ & $0.69^{* *}$ & & $0.80^{* *}$ \\
(11) Apathetic & -0.11 & 0.03 & -0.03 & 0.24 & -0.19 & -0.15 & -0.14 & $0.88^{* *}$ & $0.78^{* *}$ & $0.58^{* *}$ & \\
\hline
\end{tabular}

${ }^{* *} p<0.01 ;{ }^{*} p<0.05$

Note: Perason's correlations for men are above the diagonal; correlations for women are below the diagonal.

Table 3. Results of multiple regression analyses in relation to testosterone levels

\begin{tabular}{lccccc}
\hline & \multicolumn{2}{c}{ Men } & & \multicolumn{2}{c}{ Women } \\
\cline { 2 - 3 } \cline { 6 - 6 } & Standardized-beta & $p$ & & Standardized-beta & $p$ \\
\hline Age & 0.01 & 0.98 & & -0.68 & 0.017 \\
Marrital status $^{\#}$ & -0.99 & 0.065 & & 0.21 & 0.30 \\
Smoking status $^{\#}$ & 0.46 & 0.28 & & 0.07 & 0.72 \\
Alcohol habits $^{\#}$ & 0.00 & 1.00 & & -0.11 & 0.52 \\
Physical activity $^{\#}$ & -0.12 & 0.74 & & 0.19 & 0.27 \\
Medical history & -0.41 & 0.18 & & 0.12 & 0.50 \\
Periods of service & 0.28 & 0.66 & & 0.11 & 0.62 \\
Job demands & -0.03 & 0.95 & & -0.04 & 0.82 \\
Job control & 0.59 & 0.25 & & -0.07 & 0.71 \\
Support from supervisors & -0.80 & 0.16 & & 0.31 & 0.17 \\
Support from colleagues & 0.07 & 0.83 & & -0.35 & 0.11 \\
\hline F value & 0.84 & 0.62 & & 1.16 & 0.35 \\
R-square & 0.54 & & & 0.29 & \\
Adjusted R-square & 0.10 & & 0.04 & \\
\hline
\end{tabular}

\# Dummy variables: Married as 1; Current and past smokers as 1; Drinkers as 1; Past history as 1 ; Physically active as 1 .

of testosterone levels in relation to job-stress factors and lifestyle factors. The set of lifestyle factors and job-stress factors did not significantly explain testosterone levels for men or women. With regard to the contribution of individual variables, age was negatively associated with testosterone levels in women. The Variance Inflation Factors (VIF) for explanatory variables in this multiple regression were low ( $<6.5$ for men and $<2.9$ for women), suggesting no multicollinearity problems.

Interaction effects of job-stress levels and testosterone levels on psychological stress responses

Table 4 shows the results of multiple regression analyses of stress responses in relation to testosterone levels and job- stress factors adjusted for lifestyle factors in men and women. The set of explanatory variables significantly explained aggressive responses in women. With regard to the contribution of individual variables, testosterone levels were positively associated with apathetic responses from men. For women, job demand was positively associated with the total score and aggressive responses. Support from colleagues was negatively associated with aggressive responses. The VIF for explanatory variables in this multiple regression were low $(<6.6$ for men and $<3.6$ for women).

When an interaction of job demand and testosterone was taken into the models, no significant association was found. When an interaction of job control and testosterone and that 


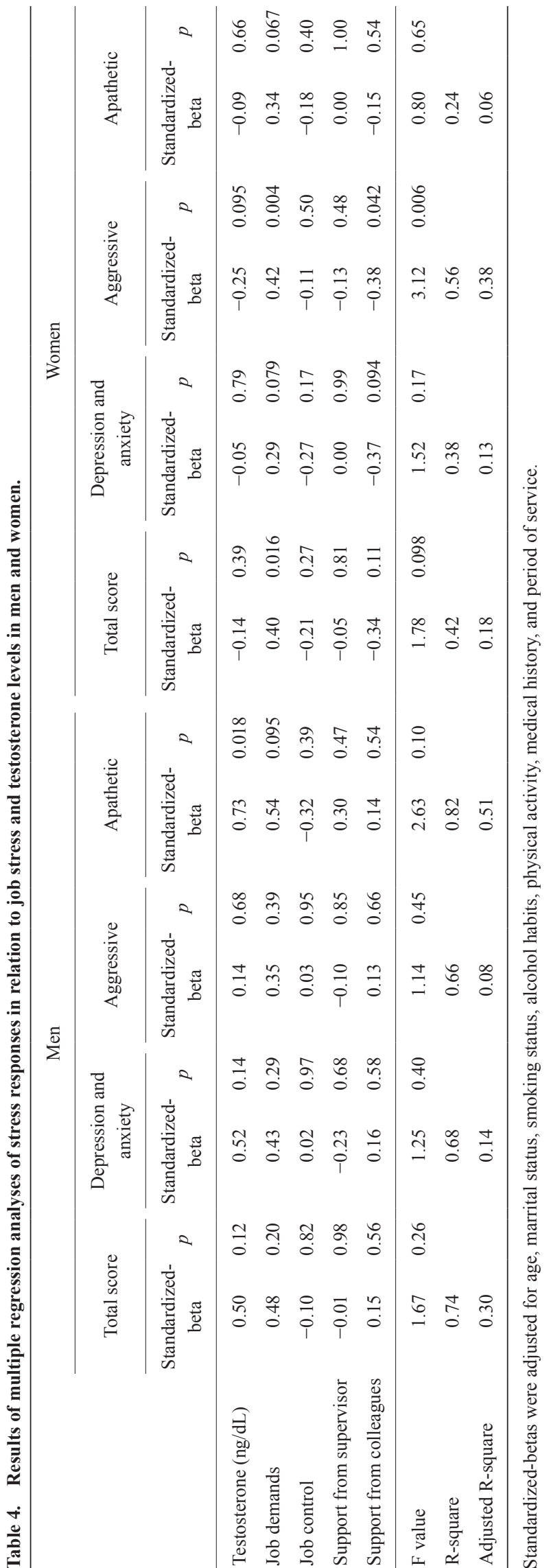

of support from supervisors and testosterone were taken into the models, no significant association was found. An interaction between support from colleagues and testosterone level was significantly associated with depression and anxiety responses in women (standardized beta $=0.44$, $p=0.020$ ). Although not significant, an interaction between support from colleagues and testosterone level showed the same trend in the total score (standardized beta $=0.35$, $p=0.062$ ) and apathetic responses (standardized beta $=0.31$, $p=0.071)$.

Figure 1 shows regression lines and predicted values illustrating the significant interaction effects of testosterone and support from colleagues on stress responses for women. A significant interaction was found in depression and anxiety. Figure 1 showed a trend: lower testosterone level and lower support from colleagues was predictive for higher depression and anxiety, whereas higher support from colleagues was predictive for lower depression and anxiety. Higher testosterone level had little effect on depression and anxiety irrespective of whether support from colleagues was high or low. Although an interaction effect on the total score did not reach significance, the graphical regression lines showed the same tendency. As for apathetic response, with lower testosterone, the tendency was identical. Conversely, with higher testosterone, lower support from colleagues was predictive for lower apathetic response, whereas higher support from colleagues was predictive for higher apathetic response.

\section{Discussion}

No significant direct association between job-stress factors and salivary testosterone levels for men or women was noted, but testosterone level was positively associated with an apathetic response in men. An interaction between testosterone level and support from colleagues had a significant influence on depression and anxiety in women. According to graphical displays of regression models for women, with lower testosterone levels, the reducing effect of support from colleagues on depression and anxiety was intensified; however, with higher levels of testosterone, levels of depression and anxiety were identical irrespective of whether support from colleagues was high or low. Sex differences in testosterone function were significant, and testosterone may be a moderator between the perceived work environment and psychological stress responses for female medical workers.

The associations between job demand and psychological stress responses are well established empirically, and are 

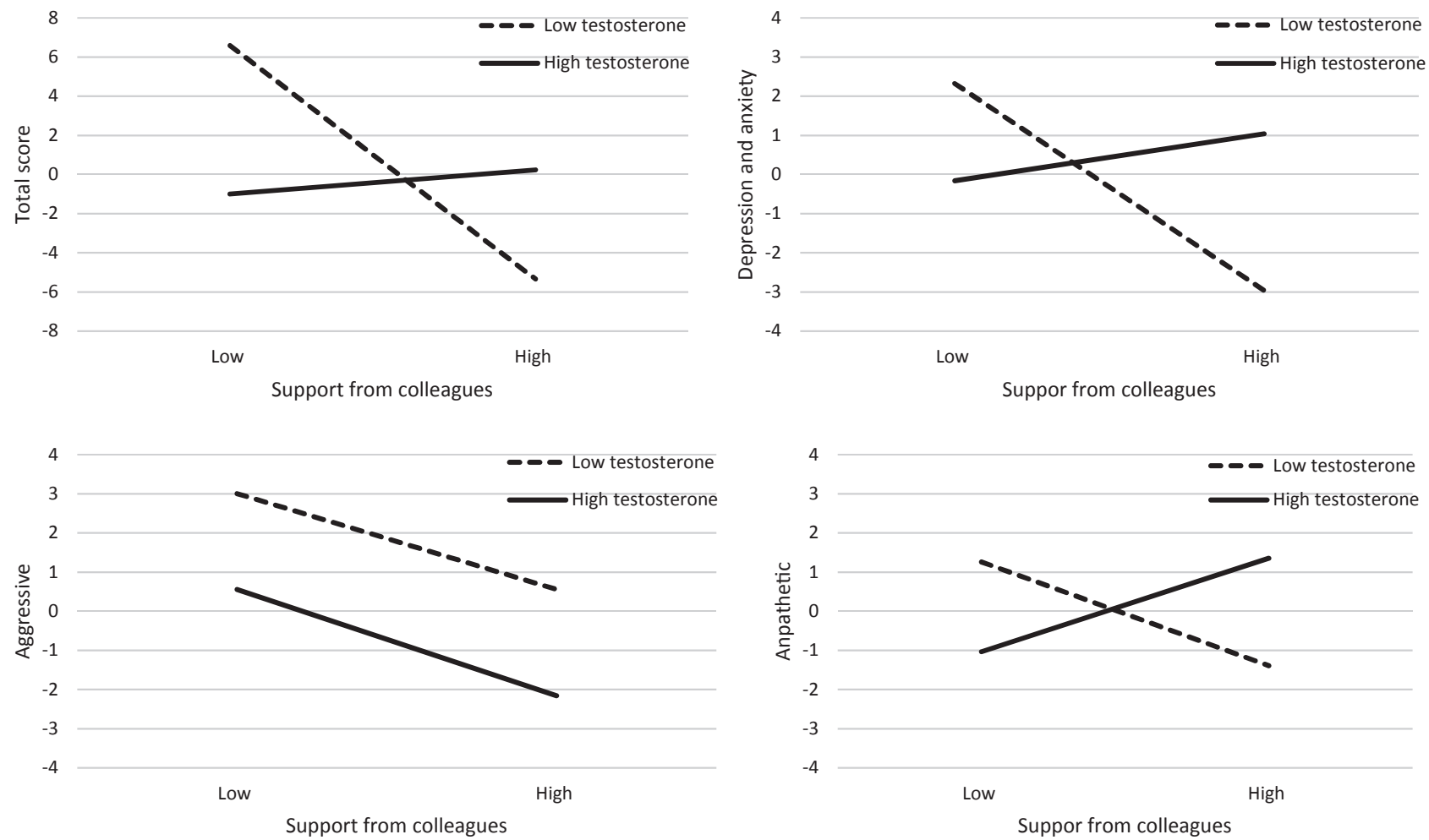

Fig. 1. Graphic display of regression lines illusitrating the interaction effects of testosterone and support from colleagues on stress responses for women.

Footnote: Regression lines were constructed from the intercepts, unstandardized regression coefficients, mean values, and standard deviations (SDs). Scores (to six significant figures for accuracy) were plotted at 1 SD below (low) the mean and 1 SD above the mean (high).

fundamental relationships described in work-stress theories $^{31)}$. Several studies have suggested that stressful work environments can cause worsened interpersonal relationships and lead to hostile and bullying behaviors ${ }^{32-34)}$. Interpersonal relationships with colleagues and with patients have been indicated to be important factors for job satisfaction among hospital nurses ${ }^{35)}$. In the present study, in women, testosterone appeared to function as a moderator between support from colleagues and depression and anxiety. Recent studies have focused on social relationships, such as connectedness with others and support from others, in relation to testosterone levels when an individual was subjected to stressors. For example, whether testosterone levels in blood increase as a reaction to stress at the initial stage is dependent upon whether an individual's social relations are stable ${ }^{12)}$. A person with physiological displays of stress may be in an unstable social relationship ${ }^{36,37)}$.

Salvador ${ }^{38)}$ discussed the associations between testosterone levels and some social interactions. Testosterone is associated mainly with aggression, competitive behavior, courtship behavior or proactive responses, and also promotes status-seeking and social dominance motives ${ }^{38,39)}$.
Furthermore, whether an individual's testosterone levels increase or decrease is dependent upon his/her subjective factors related to appraisal of the situation and, consequently, his/her stress response is dependent upon previous experiences and how they are interpreted ${ }^{38)}$. Testosterone responses are moderated by complex psychological pro$\operatorname{cesses}^{38,40)}$. In the present study, for women with lower testosterone levels, support from colleagues may have been effective in reducing psychological stress responses. For women with higher testosterone levels, support from colleagues may have been less effective, and instead may have increased psychological stress responses. This finding may be based on an individuals' appraisal of support from colleagues. For female medical workers, stable relationships with colleagues may be an important factor in reducing stress responses. Furthermore, cognitive appraisal of support at work may differ depending on testosterone levels. For example, women with high testosterone levels may feel the need to be dominant at work.

In the present study, there was a significant sex difference in associations between testosterone and stress responses. Testosterone was positively associated with apa- 
thetic response in men. We could not reveal a clear reason why testosterone functioned differently for men and women in relation to stress responses. One reason may be a small sample size for men. However, one study showed a different tendency of testosterone between men and women when participants were subjected to a stress task of a social relationship ${ }^{41}$. In that study, testosterone levels in men increased after participation in a game which made participants feel included in a team, whereas testosterone levels in women were decreased. Seidel et al. ${ }^{41)}$ attributed such increases in testosterone levels in men to their higher sensitivity to social-status motives. The present study showed a tendency whereby women with higher testosterone had higher apathetic response when they perceived high supports from their colleagues. Testosterone has been revealed to be related to dominance ${ }^{38,39)}$, and the effects on psychological functioning and social behavior between men and women could be different.

Furthermore, sex differences in cognitive appraisal of situations are known to be related to stress and psychological and/or physical stress responses. Several review studies $^{42,43)}$ have focused on the hypothalamic-pituitaryadrenal (HPA) axis. The HPA axis is a major component of a system that responds to stress because it coordinates neuroendocrine and autonomic responses. The HPA axis can interact with the gonadal hormone system, and such interactions may mediate the sex differences stated above $e^{42,43)}$. For example, enhanced responses to stress are most prevalent when estradiol levels are greatest, and progesterone may reduce the effects of estradiol on the function of the HPA axis across the reproductive cycle in women ${ }^{43}$. Androgens (which circulate more in men than in women) may inhibit the activity of the HPA axis ${ }^{43}$. In addition to the effects of gonadal hormones on stress responses, neurotransmitters (e.g., norepinephrine, serotonin) may affect the activity of HPA axis and may be linked to sex differences $^{42)}$. In the present study, several unmeasured factors could have explained the effects of testosterone on stress responses in men and women.

The present study had limitations. The cross-sectional nature of the study did not permit causal interpretation, and the sample size was small (especially for men). Attendees of the health-education programs offered by the organizations participated voluntarily. In total, $81.2 \%$ of the attendees participated in the saliva collection. The strength of the associations may have been weakened by dropouts. Participants were not instructed to refrain from eating, drinking, or smoking tobacco before saliva collections. Such behavior before saliva collection could have affected the reliabil- ity of saliva determinations. Furthermore, although saliva, plasma, and serum steroid hormones are highly correlated, salivary measures show lower concentrations than plasma and serum samples, and may vary considerably from those samples $^{44)}$. Measurement of testosterone levels in saliva would make interpretation difficult when comparing testosterone levels in serum. However, collecting saliva samples within a health education program at workplaces is noninvasive. Use of cotton swabs may also affect the reliability and validity of testosterone samples. In the present study, testosterone levels were consistent when they were collected twice among participants. A mean of salivary testosterone measured by tube without cotton was 0.18 (range: $0.03-0.36) \mathrm{ng} / \mathrm{mL}$ for 65 Japanese men and women ${ }^{45)}$. Use of cotton swabs increased testosterone levels compared to non-use of cotton swabs ${ }^{46}$. Because of those limitations relating to reliability and validity of the measurement of salivary testosterone levels as explained above, the results of the present study were required considerable attention.

In conclusion, among Japanese medical workers, a significant sex difference was found in associations between saliva levels of testosterone and stress responses. In men, testosterone was positively associated with apathetic response whereas, in women, an interaction of testosterone and support from colleagues on depression and anxiety was significant. Testosterone may have different effects on associations between job-stress factors and stress responses for men and women. Further research will be necessary to examine adequately the role of testosterone as it relates to social behavior and psychological stress.

\section{Acknowledgment}

This study was supported in part by a Grant-in-Aid from the Japanese Ministry of Education, Culture, Sports, Science and Technology (grant number 17700527).

\section{References}

1) Miki A (2002) Stress management in hospitals. Sangyo Eiseigaku Zasshi 44, 219-23 (in Japanese).

2) Karasek RA (1979) Job demands, job decision latitude, and mental strain: Implications for job redesign. Adm Sci Q 24, $258-308$.

3) Karasek R, Brisson C, Kawakami N, Houtman I, Bongers P, Amick B (1998) The Job Content Questionnaire (JCQ): an instrument for internationally comparative assessments of psychosocial job characteristics. J Occup Health Psychol 3, $322-55$.

4) Johnson JV, Hall EM (1988) Job strain, work place social 
support, and cardiovascular disease: a cross-sectional study of a random sample of the Swedish working population. Am J Public Health 78, 1336-42.

5) Saijo Y, Yoshioka E, Kawanishi Y, Nakagi Y, Itoh T, Yoshida $\mathrm{T}$ (2015) Relationships of job demand, job control, and social support on intention to leave and depressive symptoms in Japanese nurses. Ind Health Advance online publication. https://www.jstage.jst.go.jp/article/indhealth/advpub/0/advpub_2015-0083/_pdf Accessed September 3, 2015.

6) Theorell T, Karasek RA, Eneroth P (1990) Job strain variations in relation to plasma testosterone fluctuations in working men - a longitudinal study. J Intern Med 227, 31-6.

7) Theorell T, Harms-Ringdahl K, Ahlberg-Hultén G, Westin B (1991) Psychosocial job factors and symptoms from the locomotor system - a multicausal analysis. Scand J Rehabil Med 23, 165-73.

8) Kaergaard A, Hansen ÅM, Rasmussen K, Andersen JH (2000) Association between plasma testosterone and workrelated neck and shoulder disorders among female workers. Scand J Work Environ Health 26, 292-8.

9) Knol BW (1991) Stress and the endocrine hypothalamuspituitary-testis system: a review. Vet Q 13, 104-14.

10) Hansen AM, Larsen AD, Rugulies R, Garde AH, Knudsen LE (2009) A review of the effect of the psychosocial working environment on physiological changes in blood and urine. Basic Clin Pharmacol Toxicol 105, 73-83.

11) Amikishieva AV (2007) Testosterone and behavior: involvement of the hormone in psychotropic effects of baclofen. Bull Exp Biol Med 143, 259-63.

12) Chichinadze K, Chichinadze N (2008) Stress-induced increase of testosterone: contributions of social status and sympathetic reactivity. Physiol Behav 94, 595-603.

13) Gao HB, Tong MH, Hu YQ, Guo QS, Ge R, Hardy MP (2002) Glucocorticoid induces apoptosis in rat leydig cells. Endocrinology 143, 130-8.

14) Hardy MP, Gao HB, Dong Q, Ge R, Wang Q, Chai WR, Feng X, Sottas C (2005) Stress hormone and male reproductive function. Cell Tissue Res 322, 147-53.

15) Chiocchio SR, Suburo AM, Vladucic E, Zhu BC, Charreau E, Décima EE, Tramezzani JH (1999) Differential effects of superior and inferior spermatic nerves on testosterone secretion and spermatic blood flow in cats. Endocrinology 140, 1036-43.

16) Serrano MA, Moya-Albiol L, Salvador A (2014) Endocrine and mood responses to two working days in female teachers. Span J Psychol 17, E25.

17) Axelsson J, Åkerstedt $\mathrm{T}$, Kecklund $\mathrm{G}$, Lindqvist A, Attefors R (2003) Hormonal changes in satisfied and dissatisfied shift workers across a shift cycle. J Appl Physiol 95, 2099-105.

18) Persson R, Ørbaek P, Kecklund G, Akerstedt T (2006) Impact of an 84-hour workweek on biomarkers for stress, metabolic processes and diurnal rhythm. Scand J Work Environ Health 32, 349-58.

19) Ohlson CG, Söderfeldt M, Söderfeldt B, Jones I, Theorell T
(2001) Stress markers in relation to job strain in human service organizations. Psychother Psychosom 70, 268-75.

20) Grossi G, Theorell T, Jürisoo M, Setterlind S (1999) Psychophysiological correlates of organizational change and threat of unemployment among police inspectors. Integr Physiol Behav Sci 34, 30-42.

21) Fannin N, Dabbs JM Jr (2003) Testosterone and the work of firefighters: Fighting fires and delivering medical care. J Res Pers 37, 107-15.

22) Hockey GR (1997) Compensatory control in the regulation of human performance under stress and high workload; a cognitive-energetical framework. Biol Psychol 45, 73-93.

23) Singer F, Zumoff B (1992) Subnormal serum testosterone levels in male internal medicine residents. Steroids 57, $86-9$.

24) Brennan PA, Herd MK, Puxeddu R, Anand R, Cascarini L, Brown JS, Avery CM, Woodwards RT, Mitchell DA (2011) Serum testosterone levels in surgeons during major head and neck cancer surgery: a suppositional study. Br J Oral Maxillofac Surg 49, 190-3.

25) Kawakami N, Kobayashi F, Araki S, Haratani T, Furui H (1995) Assessment of job stress dimensions based on the job demands- control model of employees of telecommunication and electric power companies in Japan: reliability and validity of the Japanese version of the Job Content Questionnaire. Int J Behav Med 2, 358-75.

26) Karasek R (1985) Job Content Questionnaire. Los Angeles, CA: Department of Industrial and Systems Engineering, University of Southern California.

27) Suzuki S, Shimada H, Miura M, Katayanagi K, Umano R, Sakano Y (1997) Development of a new psychological stress response scale (SRS-18) and investigation of the reliability and the validity. Jpn J Behav Med 4, 22-9 (in Japanese).

28) Jaccard J, Turrisi R, Wan CK (1990) Interaction effects in multiple regression. Sage: Newbury Park, CA, USA

29) Cohen J, Cohen P, West SG, Aiken LS (2003) Applied multiple regression/correlation analysis for the behavioral sciences, 2nd ed. Erlbaum: Hillsdale, MI, USA

30) Takaki J (2013) Circulating nitrite and nitrate are associated with job-related fatigue in women, but not in men. Int $\mathrm{J}$ Environ Res Public Health 10, 2813-24.

31) Shaufeli WB, Bakker AB, van Rhenen W (2009) How changes in job demands and resources predict burnout, work engagement, and sickness absenteeism. J Organ Behav 30, 893-917.

32) Matthiesen SB, Einarsen S (2007) Perpetrators and targets of bullying at work: role stress and individual differences. Violence Vict 22, 735-53.

33) Felblinger DM (2009) Bullying, incivility, and disruptive behaviors in the healthcare setting: identification, impact, and intervention. Front Health Serv Manage 25, 13-23.

34) Takaki J, Taniguchi T, Fukuoka E, Fujii Y, Tsutsumi A, Nakajima K, Hirokawa K (2010) Workplace bullying could play important roles in the relationships between job strain 
and symptoms of depression and sleep disturbance. J Occup Health 52, 367-74.

35) Utriainen K, Kyngäs H (2009) Hospital nurses' job satisfaction: a literature review. J Nurs Manag 17, 1002-10.

36) Creel S (2001) Social dominance and stress hormones. Trends Ecol Evol 16, 491-7.

37) Sapolsky RM (2005) The influence of social hierarchy on primate health. Science 308, 648-52.

38) Salvador A (2012) Steroid hormones and some evolutionary-relevant social interactions. Motiv Emot 36, 74-83.

39) Eisenegger C, Haushofer J, Fehr E (2011) The role of testosterone in social interaction. Trends Cogn Sci 15, 263-71.

40) Salvador A, Costa R (2009) Coping with competition: neuroendocrine responses and cognitive variables. Neurosci Biobehav Rev 33, 160-70.

41) Seidel EM, Silani G, Metzler H, Thaler H, Lamm C, Gur RC, Kryspin-Exner I, Habel U, Derntl B (2013) The impact of social exclusion vs. inclusion on subjective and hormonal reactions in females and males. Psychoneuroendocrinology 38, 2925-32.

42) Goel N, Workman JL, Lee TT, Innala L, Viau V (2014) Sex differences in the HPA axis. Compr Physiol 4, 1121-55.

43) Handa RJ, Weiser MJ (2014) Gonadal steroid hormones and the hypothalamo-pituitary-adrenal axis. Front Neuroendocrinol 35, 197-220.

44) Kirschbaum C, Hellhammer DH (1989) Salivary cortisol in psychobiological research: an overview. Neuropsychobiology 22, 150-69.

45) Mita K, Matsubara A, Usui T (2005) Measurement of salivary testosterone by a simple enzyme immunoassay procedure. Nippon Hinyokika Gakkai Zasshi 96, 610-6.

46) Katsumata M, Hirata K, Inagaki H, Hirata $Y$, Kawada $T$ (2009) Evaluation of new saliva collection device for determination of salivary cotinine, cortisol, dehydroepiandrosterone and testosterone concentrations. Nippon Eiseigaku Zasshi 64, 811-6. 